\title{
Benzoik Asit Esterlerinin Sentez, Yapı Açıklamaları ve Kan- titatif Lokal Anestezik Etkileri Üzerinde Çalışmalar - II
}

Studies on the Synthesis, Structure Elucidation and Quantitative Local Anesthetic Activities of Benzoic Acid Esters - II

\author{
Tuncel ÖZDEN*
}

\section{ÖZET}

Bu çalışmada lokal anestezik etkili, 2,4-dimetoksi ve 2.4-dimetilbenzoik asitin 2-dialkilaminoetil esterleri hazırlanmış ve 7 si orjinal olan 10 bileşiğin yapıları kanıtlandıktan sonra kantitatiflokal anestezik etkileri prokain hidroklorür ile de mukayese edilerek verilmiştir. Sonuçta. 2.4-dimetilbenzolik asitin 2-dialkilaminoetil esterleri, 2,4-dimetoksibenzoik asit esterleri ve prokain HC1 den daha etkili bulunmuştur.

\section{SUMMARY}

In this research, 10. 2-dialkylaminoethyl esters of 2,4-dimethoxy and 2,4-dimethylbenzoic acids had been prepared and 7 of them were original. After the structure elucidation their local anesthetic activities were found and compared with the activity of procain hydrochloride. As a result, 2-dialkylaminoethyl esters of 2,4-dimethylbenzoic acid were found more active than esters of 2,4-dimethoxybenzoic acids and procaine $\mathrm{HC} 1$.

Anahtar Kelimeler: Lokal Anestezi; Substitue benzoik asit; Esterler; Prokain $\mathrm{HCl}$ 
Benzoik asit esteri lokal anestczik etkili bileşiklerde orto konumunda bulunan sübstitüentlerin etkiye katkılarının açıklanması amacryla sentezlenen monosübstitüe benzoik asit esterlerinin sentezleri ve yapılarının açıklanması bundan önceki çalışmada verilmişti (1). $\mathrm{Bu}$ çalışmada da orto ve para disübstitüe benzoik asit türevleri ele alınmış ve 2,4-dimetoksi ve 2,4-dimetilbenzoik asitin 2-dialkilaminoetil esterlerinin sentezi, yapılarının açıklanması ve lokal anestezik etkileri ortaya konulmuştur.

\section{DENEL KISIM}

\section{Materyal ve Metod}

Çalışmada kullanılan, 2,4-dimetilbenzoik asit (Ega) saf bileşiktir. 2,4-Dimetoksibenzoik asit ise 2,4-dihidroksibenzoik asitten hareketle hazırlanmıştır. 2-Dialkilaminoetil klorür hidroklorür bileşikleri ise 2-kloroetanol ve uygun dialkilaminlerden hareketle 2-dialkilaminoetanol basamağından geçilerek hazırlanmıştır (1).

Aletsel analiz çalışmalarında spektral saflıkta potasyum bromür (Pye Unicam), metanol (Aldrich) ve dimctilsulfoksit-d 6 (J.T. Baker) kullanılmıştır.

Sentezlenen bileşiklerin UV spektrumları Pye Unicam SP 1700 Ultraviyole Spektrofotomctresi, İR spektrumlari Pye Unicam SP 1100 İnfrared Spektrofotometresi, NMR spektrumları Varian A-60 N M R Spektrometresi, kütle spektrumları Hitachi-Perkin Elmer Kütle Spektrometresi kullanılarak alınmıştır. Ergime dereceleri Mettler FP-5 Ergime Derecesi Tayin Cihazından yararlanılarak bulunmuş ve düzeltilmeden verilmiştir.

\section{2,4-Dimetoksibenzoik Asit Sentezi}

$24.66 \mathrm{~g}(0.16 \mathrm{~mol})$ o,p-dihidrosibenzoik asit ve $56 \mathrm{~g}$ (1 mol) potasyum hidroksitin $200 \mathrm{ml}$ distile su içindeki çözeltisi $500 \mathrm{ml}$ lik yuvarlak dipli bir balonda karıştırıldı. Karışıma 100.90 g (0.8 mol) dimetil sülfat ilave edildi. Balon içeriği yă̆ banyosu ve manyetik karıştırıcı üzerinde, geri çeviren soğutucu altında, $130{ }^{\circ} \mathrm{C}$ de 4 saat 1sıtıldı. Bu süre sonunda karışımdan bir miktar alındı, üzerine $6 \mathrm{~N}$ hidroklorik asit çözeltisi ilavesiyle çöktürülen bileşik süzülerek alındı, 
yıkama suları asit reaksiyon vermiyene kadar distile su ile yıkandı. Çökelek metanol içinde çözüldü ve \% 5 lik demir-3-klorür çözeltisi ilavesiyle fenol grubunun varlığ 1 araştırıldı. Fenol grubunun varlığ görülmediğinden reaksiyona son verildi. Reaksiyon karışımı soğutuldu, süzüldü ve süzüntüye $6 \mathrm{~N}$ hidroklorik asit çözeltisi ilavesiyle bileşiğin tamamı çöktürüldü. Yıkama suları asit reaksiyon vermiyene kadar distile su ile yıkandı, kurutuldu ve metanol-aseton karışımından tekrar kristallendirilip vakum etüvünde $50{ }^{\circ} \mathrm{C}$ de kurutuldu. (Verim: \% 65.36) E.d.: $108.9{ }^{\circ} \mathrm{C}$

Sentez edilen bileşiğin E.d. ve İR spektrumu literatür verileri ile tamamen uyuşmaktadır (3).

\section{Benzoik Asit Esteri Lokal Anestezik Bileşiklerin Sentezi}

Bileşiklerin sentezi daha önce yapılan çalışmada verilen yöntemle yapılmıştır (1). Sentezlenen bileşikler Tablo: 1 de toplu halde verilmektedir. Tablodan görüldüğü gibi 10 bileşiğin 7 si ilk kez bu çalışmada sentezlenmiştir.

\section{Bileşiklerin incelenmesi}

UV Spektrumları: Tüm bileşiklerin UV spektrumları spektral saflıkta metanol içinde, $2 \times 10^{-5}$ M çözeltilerinden alınmış ve 190-400 $11 \mathrm{~m}$ arasında tarama yapılmıştır. Her bileşik için maksimum dalga boyu ve molar ekstinksiyon katsayısı değerleri verilmektedir.

İR Spektrumları: Bileşiklerin İR spektrumları potasyum bromür disk yöntemi kullanılarak alınmıştır. Aşağıda verilen pikler tüm spektrumlarda görülmektedir: 3050-3000 (=C-H gerilimleri), 2980-2850 (-C-H gerilimleri), 2600-2480 ( $\mathrm{N}+\mathrm{H}$ gerilimleri). 1750-1730 ( C = O gerilimleri), 1610-1500 ( $\mathrm{C}=\mathrm{C}$ gerilimleri), 1470-1380 (C-H eğilimleri), 1300-1010 (C-O gerilimleri), 850-770 (C-H plan dış1 eğilimleri)

Yukarıda verilenlerin dışında karakteristik pik görülmemektedir. Bu sebeple her bileşiğin spektrumunun ayrı ayrı incelenmesine gerek duyulmamıştır.

NMR Spektrumları: Bileşiklerin NMR spektrumları, DMSO-d içinde ve tetrametilsilan internal standartı kullanılarak çekilmiştir. Sentezlenen her bileşiğin NMR spektrumu ayrı ayrı çözümlenmek- 


\begin{tabular}{|c|c|c|c|c|c|}
\hline $\begin{array}{l}\text { Bil. } \\
\text { No. }\end{array}$ & $R_{1}$ & $\mathbf{R}_{2}$ & $\begin{array}{l}\text { Bil. } \\
\text { No. }\end{array}$ & $\mathbf{R}_{1}$ & $\mathbf{R}_{2}$ \\
\hline $1^{*}$ & $\mathrm{CH}_{3}$ & M e & $\begin{array}{c}6 \\
\text { Lit . } 5\end{array}$ & $\mathrm{OCH}_{3}$ & M e \\
\hline $\begin{array}{r}2 \\
\text { Lit. } \quad 4\end{array}$ & $\mathrm{CH}_{3}$ & Et & $\begin{array}{c}7 \\
\text { Lit . } 5\end{array}$ & $\mathrm{OCH}_{3}$ & Et \\
\hline $3^{*}$ & $\mathrm{CH}_{3}$ & $n-P r$ & $8^{*}$ & $\mathrm{OC} \mathrm{H}_{3}$ & $n-P r$ \\
\hline * & $\mathrm{CH}_{3}$ & i-Pr & $9^{*}$ & $\mathrm{OC} \mathrm{H}_{3}$ & i-Pr \\
\hline $5^{*}$ & $\mathrm{CH}_{3}$ & $\mathrm{n}-\mathbf{B} \mathbf{u}$ & $10 *$ & $\mathrm{OC} \mathrm{H}_{3}$ & $\mathrm{n}-\mathbf{B} \mathbf{u}$ \\
\hline
\end{tabular}

* İlk kez bu çalışmada sentezlenmiştir.

Tablo 1: Sentez edilen Bileşikler

tedir. Spektrumların bazılarında tersiyer amin tuzuna ait protonun sinyali çözücü etkisiyle görülmediğinden spektrumların çözümlenmesinde değerlendirilmemiştir.

Kütle Spektrumları: Sentezlenen tüm bileşiklerin kütle spektrumları çekilmiştir. Spektrumlar, yan zincirlerin kopuşu bakımından benzerdir ve her bileşik için ayrı ayrı açıklanmaktadır. Spektrumlarda aromatik halkanın parçalanması ile oluşan iyonlar yan zincirin parçalanma ürünleri ile karıştı̆̆ından çözümlenmemiştir.

\section{1) 2-Dimetilaminoetil o,p-dimetilbenzoat Hidroklorür}

$1.95 \mathrm{~g}(0.013 \mathrm{~mol})$, o.p-dimetilbenzoik asit, $1.87 \mathrm{~g}(0.013 \mathrm{~mol})$ 2 -dimetilaminoetil klorür hidroklorür ve $2.63 \mathrm{~g}(0.026 \mathrm{~mol})$ trietila- 
min kullanılan sentez sonunda $2.63 \mathrm{~g}$ saf bileşik elde edildi. (Verim: $\%$ 78.57) E.d.: $120.0{ }^{\circ} \mathrm{C}$

UV Spektrumu: $\lambda$ maks. $207 \quad(\varepsilon=20550), 242 \quad(\varepsilon=10700)$ ve 281 $i \varepsilon=500) \quad \mathrm{nm}$

NMR Spektrumu: $\delta$ ppm. 2.45 (para konumundaki metil protonları, $3 \mathrm{H}, \mathrm{s}$ ), 2.67 (orto konumundaki metil protonlar1, 3H,s), 3.00 (azota bağlı metil protonları, 6H,s), 3.68 (azota bağlı metilen protonları, $2 \mathrm{H}, \mathrm{t}$ ), 4.87 (oksijene bağlı metilen protonları, 2H,t), 7.40 (benzen halkasinın $\mathrm{m}$ protonu, $1 \mathrm{H}, \mathrm{s}$ ), 7.53 (benzen halkasinın $\mathrm{m}^{\prime}$ protonu, $1 \mathrm{H}, \mathrm{d}$ ), 8.27 (benzen halkasinın o' protonu, $1 \mathrm{H}, \mathrm{d}$ )

Kütle Spektrumu:

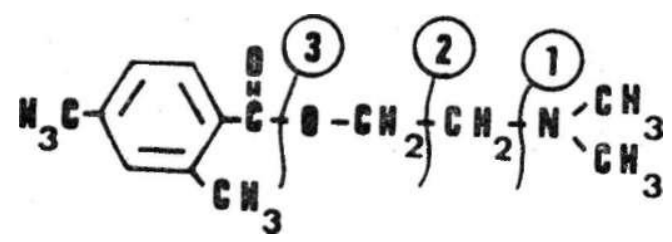

$$
\text { M+ } 221 \text { (Moleküler İyon, \% 3.73) }
$$

$\begin{array}{llll}\text { 1) } \mathrm{m} / \mathrm{e} 177(\mathrm{M}+-44, \% 43.28) & \text { 2) } \mathrm{m} / \mathrm{e} 58 \text { (Ana pik, \% 100) }\end{array}$

3) $\mathrm{m} / \mathrm{e} 133(\mathrm{M}+-88), \%$ 68.95)

\section{2) 2-Dietilaminoetil o,p-dimetilbenzoat Hidroklorür}

$1.95 \mathrm{~g}(0.013 \mathrm{~mol})$, o.p-dimetilbenzoik asit, $1.95 \mathrm{~g}(0.013 \mathrm{~mol})$ 2-dietilaminoetil klorür hidroklorür ve $2.63 \mathrm{~g}(0.026 \mathrm{~mol})$ trietilamin kullanılan sentez sonunda $2.84 \mathrm{~g}$ saf bileşik elde edildi. (Verim: \% 76.52) E.d.: $141.2{ }^{\circ} \mathrm{C}$

UV Spektrumu: $\lambda$ maks. $207 \quad(\varepsilon:=26350), 242 \quad(\varepsilon=14000)$ ve 281 $(\varepsilon=1050) \quad \mathrm{nm}$

NMR Spektrumu: $\delta$ ppm. 1.33 (etil gruplarinın metil protonlar1, $6 \mathrm{H}, \mathrm{t}$ ), 2.45 (para konumundaki metil protonlar $1,3 \mathrm{H}, \mathrm{s}$ ), 2.60 (orto 
konumundaki metil protonları, 3H,s), 3.10-3.90 (azota bağlı metilen protonları, $6 \mathrm{H}, \mathrm{m}$ ), 4.68 (oksijene bağlı metilen protonları, $2 \mathrm{H}, \mathrm{t}$ ), 7.40 (benzen halkasının $\mathrm{m}$ protonu, $1 \mathrm{H}, \mathrm{s}$ ), 7.53 (benzen halkasının m' protonu, $1 \mathrm{H}, \mathrm{d}$ ), 8.27 (benzen halkasının o' protonu, 1H,d)

Kütle Spektrumu:

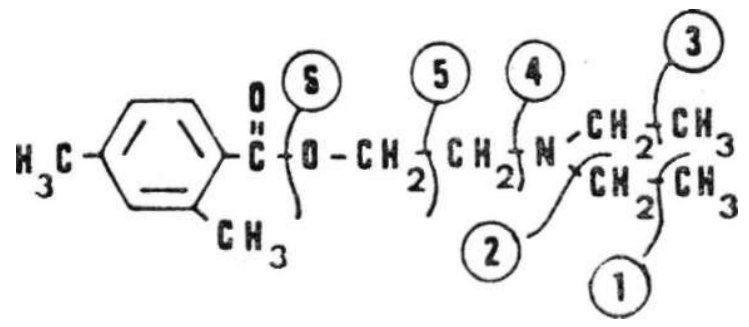

M 249 (Moleküler İyon, \% 11.94)
1) $\mathrm{m} / \mathrm{e} 234(\mathrm{M}+-15, \% 22.39)$
2) $\mathrm{m} / \mathrm{e} 220(\mathrm{M}+-29, \quad \% 25.97)$
3) $\mathrm{m} / \mathrm{e} 205(\mathrm{M}+-44, \% 4.48)$
4) $\mathrm{m} / \mathrm{e} 177(\mathrm{M}+-72, \%$ 62.69)
5) $\mathrm{m} / \mathrm{e} 86$ (Ana pik, \% 100)
6) $\mathrm{m} / \mathrm{e} 133 \mathrm{M} \quad 116, \% 86.56)$

\section{3) 2-Di-n-propilaminoetil o,p-dimetilbenzoat Hidroklorür}

$1.95 \mathrm{~g}(0.013 \mathrm{~mol})$, o,p-dimetilbenzoik asit, $2.60 \mathrm{~g}(0.013 \mathrm{~mol})$ 2-di-n-propilaminoetil klorür hidroklorür ve $2.63 \mathrm{~g}(0.026 \mathrm{~mol})$ trietilamin kullanılan sentez sonunda $3.17 \mathrm{~g}$ saf bileşik elde edildi. (Verim: $\%$ 70.58) $\quad$ E.d.: $147.2{ }^{\circ} \mathrm{C}$

UV Spektrumu: $\lambda$ maks. $207 \quad(\varepsilon=24350), 242 \quad(\varepsilon=12400)$ ve 281 $(\varepsilon=550) \quad \mathrm{nm}$

NMR Spektrumu: $\delta$ ppm. 0.83 (propil gruplarının metil protonları, $6 \mathrm{H}, \mathrm{t}$ ), 1.40-2.00 (propil gruplarının metillere komşu metilen protonlar1, 4H,m), 2.40 (para konumundaki metil protonlar1, $3 \mathrm{H}, \mathrm{s}$ ), 2.57 (orto konumundaki metil protonları, 3H,s), 2.80-3.78 (azota bağl1 metilen protonları, $2 \mathrm{H}, \mathrm{t}$ ), 4.77 (oksijene bağlı metilen protonları, $2 \mathrm{H}, \mathrm{t}$ ), 7.33 (benzen halkasinın $\mathrm{m}$ protonu, $1 \mathrm{H}, \mathrm{s}$ ), 7.47 (benzen hal- 
kasının m' protonu, $1 \mathrm{H}, \mathrm{d}$ ), 8.12 (benzen halkasinın o' protonu, $1 \mathrm{H}, \mathrm{d})$

Kütle Spektrumu:

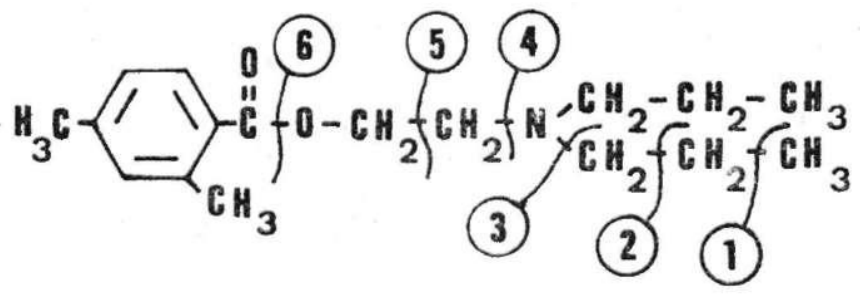

$$
\text { M+ } 277 \text { (Moleküler İyon, \% 23.08) }
$$
1) $\mathrm{m} / \mathrm{e} 262(\mathrm{M}+-15, \% 7.69)$
2) $\mathrm{m} / \mathrm{e} 248(\mathrm{M}+-29, \% 83.08)$
3) $\mathrm{m} / \mathrm{e} 234(\mathrm{M}+-43, \% 6.50)$
4) $\mathrm{m} / \mathrm{e} 177(\mathrm{M}+-100, \% 93.85)$
5) $\mathrm{m} / \mathrm{e} 114$ (Ana pik, \% 100)
6) $\mathrm{m} / \mathrm{e} 133 \mathrm{M} \quad 144, \%$ 99.00)

\section{4) 2 -Diizopropilaminoetil o,p-dimetilbenzoat Hidroklorür}

$1.95 \mathrm{~g}(0.013 \mathrm{~mol})$ o,p-dimetilbenzoik asit, $2.60 \mathrm{~g} \quad(0.013 \mathrm{~mol})$ 2-diizopropilaminoetil klorür hidroklorür ve $2.63 \mathrm{~g}(0.026 \mathrm{~mol})$ trietilamin kullanılan sentez sonunda 3.31 g saf bileşik elde edildi. (Verim: $\%$ 73.70) E.d.: $139.3{ }^{\circ} \mathrm{G}$

UV Spektrumu: $\lambda$ maks. $207 \quad(\varepsilon=30350), 242 \quad(\varepsilon=10750)$ ve 281 $(\varepsilon=1050) \quad \mathrm{nm}$

N M R Spektrumu: $\delta$ ppm. 1.42 (izoproil gruplarının metil protonlar $12 \mathrm{H}, \mathrm{dd}$ ). 2.40 (para konumundaki metil protonlar1, $3 \mathrm{H}, \mathrm{s}$ ), 2.62 (orto konumundaki metil protonları, 3H,s), 3.40-4.00 (azota bağl1 metilen ve metin protonları, $4 \mathrm{H}, \mathrm{m}$ ), 4.80 (oksijene bağlı metilen protonları, 2H,t), 7.38 (benzen halkasının $\mathrm{m}$ protonu, 1H,s), 7.48 (benzen halkasinın $\mathrm{m}^{\prime}$ protonu, $1 \mathrm{H}, \mathrm{d}$ ), 8.23 (benzen halkasinın o' protonu, $1 \mathrm{H}, \mathrm{d})$ 
Kütle Spektrumu:

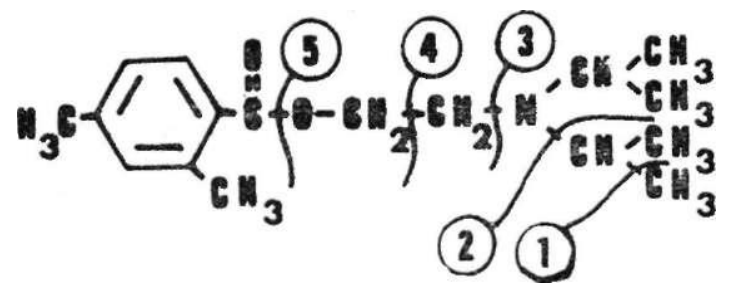

M+ 277 (Moleküler İyon, \% 24.61)
1) $\mathrm{m} / \mathrm{e} 262(\mathrm{M}+-15, \% 70.77)$
2) $\mathrm{m} / \mathrm{e} 234(\mathrm{M}+-43, \%$ 8.46)
3) $\mathrm{m} / \mathrm{e} 177(\mathrm{M}+-100, \%$ 81.54)
4) $\mathrm{m} / \mathrm{e} 114$ (Ana pik, \% 100)
5) $\mathrm{m} / \mathrm{e} 133(\mathrm{M}+-144, \%$ 89.23)

\section{5) 2-Di-n-butilaminoetil o,p-dimetilbenzoat Hidtoklorür}

$1.95 \mathrm{~g}(0.013 \mathrm{~mol})$, o.p-dimetilbenzoik asit, $2.96 \mathrm{~g}(0.013 \mathrm{~mol})$ 2-di-n-butilaminoetil klorür hidroklorür ve $2.63 \mathrm{~g}(0.026 \mathrm{~mol})$ trietilamin kullanılan sentez sonunda $3.25 \mathrm{~g}$ saf bileşik elde edildi. (Verim: $\%$ 66.94) E.d.: $144.2{ }^{\circ} \mathrm{C}$

UV Spektrumu: $\lambda$ maks. $207 \quad(\varepsilon=17150), 242 \quad(\varepsilon=7600)$ ve 281 $(\varepsilon=450) \quad \mathrm{nm}$

NMR Spektrumu: $\delta$ ppm. 0.99 (butil gruplarının metil protonlar $6 \mathrm{H}, \mathrm{t}$ ), 1.10-2.20 (butil gruplarının 2 ve 3 . konumlarındaki metilen protonları, $8 \mathrm{H}, \mathrm{m}$ ), 2.42 (para konumundaki metil protonlar1, 3H.s), 2.60 (orto konumundaki metil protonlar1, 3H,s), 3.00-4.00 (azota bağlı metilen protonları, 6H,m). 4.90 (oksijene bağlı metilen protonlar1, 2H,t), 7.40 (benzen halkasinın m protonu, 1H,s), 7.50 (benzen halkasinın $\mathrm{m}^{\prime}$ protonu, $1 \mathrm{H}, \mathrm{d}$ ), 8.20 (benzen halkasinin o' protonu, 1 H, d) 
Kütle Spektrumu :

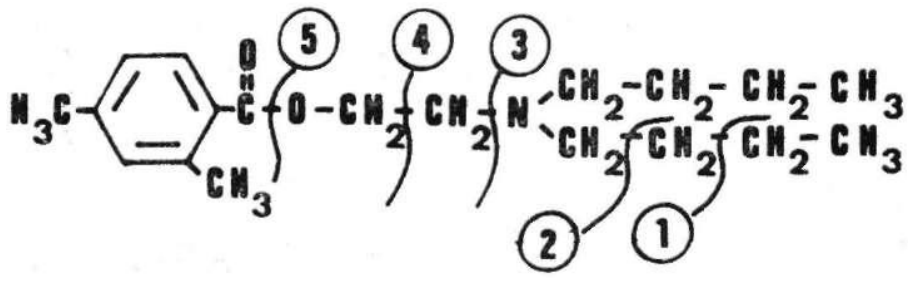

M+ 305 (Moleküler iyon, \% 6.12)
1) $\mathrm{m} / \mathrm{e} 276(\mathrm{M}+-29, \% 3.12)$
2) $\mathrm{m} / \mathrm{e} 262(\mathrm{M}+-43, \% 61,90)$
3) $\mathrm{m} / \mathrm{e} 177(\mathrm{M}+-128, \%$ 71.42)
4) $\mathrm{m} / \mathrm{e} 142$ (Ana pik, \% 100)
5) $\mathrm{m} / \mathrm{e} 133(\mathrm{M}+-172, \% 80.95)$

\section{6) 2-Dimetilaminoetil o.p-dimetoksibenzoat Hidroklorür}

$2.36 \mathrm{~g}(0.013 \mathrm{~mol})$ o,p-dimetoksibenzoik asit, $1.87 \mathrm{~g}(0.013 \mathrm{~mol})$ 2-dimetilaminoetil klorür hidroklorür ve $2.63 \mathrm{~g}(0.026 \mathrm{~mol})$ trietilamin kullanılan sentez sonunda 2.63 g saf bileşik elde edildi. (Verim: $\%$ 69.90) E.d.: $163.9{ }^{\circ} \mathrm{C}$

UV Spektrumu: $\lambda$ maks. 211 ( $\varepsilon=17600), 223$ (omuz, $\varepsilon=11000), 2475$ $(\varepsilon=10850) \quad$ ve $295 \quad(\varepsilon=2600) \quad \mathrm{nm}$

NMR: Spektrumu: $\delta$ ppm. 2.93 (azota bağlı metil protonları, 6H,s), 3.59 (azota bağlı metilen protonları, 2H,t), 4.00 (metoksil protonlar $6 \mathrm{H}, \mathrm{s}$ ), 4.75 (oksijene bağlı metilen protonları, $2 \mathrm{H}, \mathrm{t}$ ), 6.80 (benzen halkasinın $\mathrm{m}$ protonu, $1 \mathrm{H}, \mathrm{s}$ ), 6.95 (benzen halkasinın m' protonu, $1 \mathrm{H}, \mathrm{d}), 8.20$ (benzen halkasinın o' protonu, $1 \mathrm{H}, \mathrm{d}$ ) 
Kütle Spektrumu:

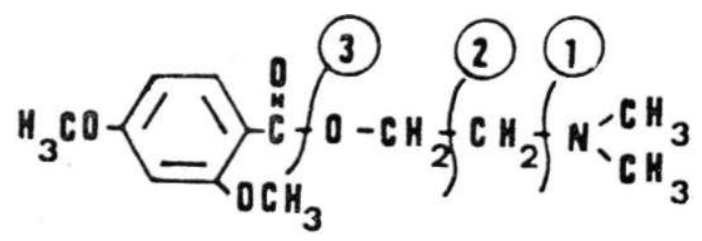

M 253 (Moleküler İyon, \% 7.57)
1) $\mathrm{m} / \mathrm{c} 209(\mathrm{M}+-44), \% 11.36)$
2) $\mathrm{m} / \mathrm{e} 58$ (Ana pik, \% 100)
3) $\mathrm{m} / \mathrm{c} 165(\mathrm{M}+-88, \% 69.69)$

\section{7) 2-Dietilaminoetil o,p-dimetoksibenzoat Hidroklorür}

$2.36 \mathrm{~g}(0.013 \mathrm{~mol})$ o,p-dimetoksibenzoik asit, $2.23 \mathrm{~g}(0.013 \mathrm{~mol})$ 2-dietilaminoetil klorür hidroklorür ve $2.63 \mathrm{~g}(0.026 \mathrm{~mol})$ trietilamin kullanılan sentez sonunda $3.10 \mathrm{~g}$ saf bileşik elde edildi. (Verim: \% 75.80) E.d.: $135.8^{\circ} \mathrm{C}$

UV Spektrumu: $\lambda$ maks. $211 \quad(\varepsilon=13750), 223$ (omuz, $\varepsilon=6850), 257$ $(\varepsilon=9900)$ ve $295 \quad(\varepsilon=4900)$

NMR Spektrumu: $\delta$ ppm. 1.30 (etil gruplarinın metil protonlar1, $6 \mathrm{H}, \mathrm{t}$ ), 3.00-3.80 (azota bağlı metilen protonları, 6H,m), 4.08 (metoksil protonları, $6 \mathrm{H}, \mathrm{s}$ ), 4.80 (oksijene bağlı metilen protonları, $2 \mathrm{H}, \mathrm{t}$ ), 6.82 (benzen halkasinın $\mathrm{m}$ protonu, $1 \mathrm{H}, \mathrm{s}$ ), 7.00 (benzen halkasinın m' protonu $1 \mathrm{H}, \mathrm{d}$ ), 8.20 (benzen halkasinın o' protonu, $1 \mathrm{H}, \mathrm{d}$ )

Kütle Spektrumu:

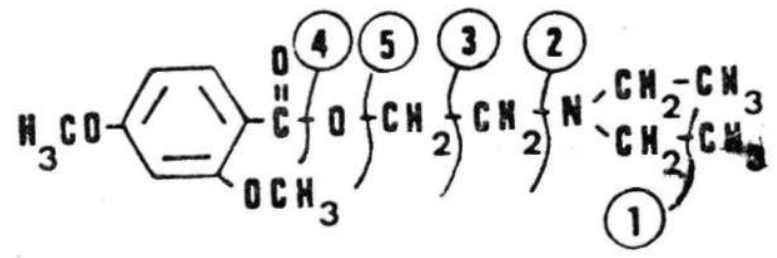
$\mathrm{M}+281$ (Moleküler İyon, \% 7.57)
1) $\mathrm{m} / \mathrm{e} 266(\mathrm{M}+-15, \% 6.15)$
2) $\mathrm{m} / \mathrm{e} 209(\mathrm{M}+-72, \% 39.39)$
3) $\mathrm{m} / \mathrm{e} 86$ (Ana pik, \% 100)
4) $\mathrm{m} / \mathrm{e} 165(\mathrm{M}+-116, \% 75.37)$
5) $\mathrm{m} / \mathrm{e} 99(\mathrm{M}+-182, \% 90.90)$ 


\section{8) 2-Di-n-propilaminoetil o,p-dimetoksibenzoat Hidroklorür}

$2.36 \mathrm{~g}(0.013 \mathrm{~mol})$, o,p-dimetoksibenzoik asit, $2.60 \mathrm{~g}(0.013 \mathrm{~mol})$ 2-di-n-propilaminoetil klorür hidroklorür ve $2.63 \mathrm{~g}(0.026 \mathrm{~mol})$ trietilamin kullanılan sentez sonunda $3.28 \mathrm{~g}$ saf bileşik elde edildi. (Verim: $\%$ 70.80) E.d.: $134.1{ }^{\circ} \mathrm{C}$

UV Spektrumu: $\lambda$ maks. $211 \quad(\varepsilon=18900), 223$ (omuz, $\varepsilon=10350), 257$ $1 \varepsilon=12800)$ ve $295(\varepsilon=5950) \quad \mathrm{nm}$

N M R Spektrumu: $\delta$ ppm. 0.97 (propil gruplarının metil protonlar1, $6 \mathrm{H}, \mathrm{t}$ ), 1.50-2.20 (propil gruplarının metile komşu metilen protonları, 4H,m), 3.00-3.81 (azota bağlı metilen protonları, 6H,m), 4.08 (metoksil protonları, $6 \mathrm{H}, \mathrm{s}$ ), 4.83 (oksijene bağlı metilen protonları, $2 \mathrm{H}, \mathrm{t}$ ), 6.83 (benzen halkasinın $\mathrm{m}$ protonu, $1 \mathrm{H}, \mathrm{s}$ ), 7.00 (benzen halkasinın m' protonu, $1 \mathrm{H}, \mathrm{d}$ ), 8.20 (benzen halkasının o' protonu, $1 \mathrm{H}, \mathrm{d}$ )

Kütle Spektrumu:

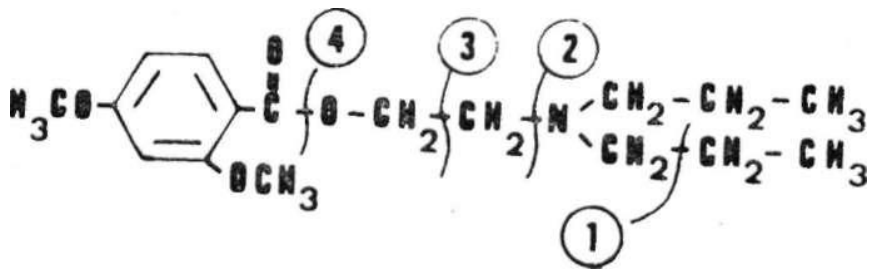

$$
\text { M+ } 309 \text { (Moleküler İyon, \% } 3.12
$$

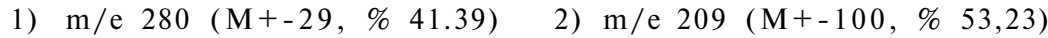

3) $\mathrm{m} / \mathrm{e} 114$ (Ana pik, \% 100) 4 4) $\mathrm{m} / \mathrm{e} 195(\mathrm{M}+-144, \% 88.70)$

\section{9) 2-Diizopropîlaminoetil o,p-dimetoksibenzoat Hidroklorür}

$2.36 \mathrm{~g}(0.013 \mathrm{~mol})$ o,p-dimetoksibenzoik asit, $2.60 \mathrm{~g}(0.013 \mathrm{~mol})$ 2-diizopropilaminoetil klorür hidroklorür ve $2.63 \mathrm{~g}(0.026 \mathrm{~mol})$ trietilamin kullanılan sentez sonunda $3.06 \mathrm{~g}$ saf bileşik elde edildi. (Verim: $\%$ 68.13) E.d.: $170.4 \quad{ }^{\circ} \mathrm{C}$

UV Spektrumu: $\lambda$ maks. $211 \quad(\varepsilon=20550), 223$ (omuz, $\varepsilon=11800)$, $257(\varepsilon=13950)$ ve $295(\varepsilon=6450) \mathrm{nm}$ 
NMR Spektrumu: $\delta$ ppm. 1.30-1.60 (izopropil gruplarinın metil protonları $12 \mathrm{H}, \mathrm{dd}$ ), 3.40-3.83 (azota bağl1 metilen ve metin protonları, 4H,m), 4.08 (metoksil protonları, 6H,s), 4.80 (oksijene bağlı metilen protonları, $2 \mathrm{H}, \mathrm{t}), 6.83$ (benzen halkasının m protonu, $1 \mathrm{H}, \mathrm{s}$ ), 7.00 (benzen halkasının $\mathrm{m}^{\prime}$ protonu, $1 \mathrm{H}, \mathrm{d}$ ), 8.23 (benzen halkasinın $\mathrm{o}^{\prime}$ protonu, $\left.1 \mathrm{H}, \mathrm{d}\right)$

Kütle Spektrumu:

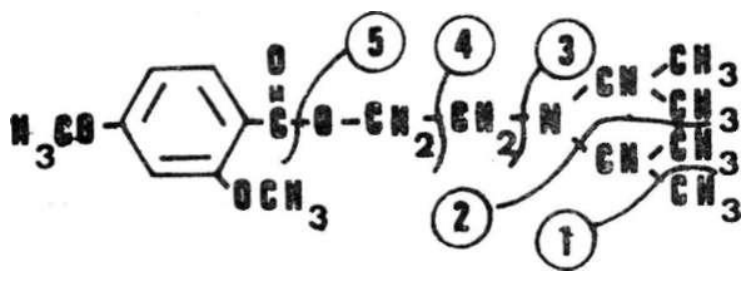

M+ 309 (Moleküler İyon, \% 6.06)
1) $\mathrm{m} / \mathrm{e} 294(\mathrm{M}+-15, \% 31.25)$
2) $\mathrm{m} / \mathrm{e} 266(\mathrm{M}+-43, \% 3.12)$
3) $\mathrm{m} / \mathrm{e} 209(\mathrm{M}+-100, \% 53.12)$
4) $\mathrm{m} / \mathrm{e} 114$ (Ana pik, \% 100)
5) $\mathrm{m} / \mathrm{e} 165(\mathrm{M}+-144, \% 71.87)$

\section{0) 2-Di-n-butilaminoetil o,p-dimetoksibenzoat Hidroklorür}

$2.36 \mathrm{~g}(0.013 \mathrm{~mol})$, o,p-dimetoksibenzoik asit, $2.96 \mathrm{~g} \mathrm{(0.013} \mathrm{mol)}$ 2-di-n-butilaminoetil klorür hidroklorür ve $2.63 \mathrm{~g}(0.026 \mathrm{~mol})$ tiretilamin kullanılan sentez sonunda $3.35 \mathrm{~g}$ saf bileşik elde edildi. (Verim: $\%$ 68.99) E.d.: $98.3{ }^{\circ} \mathrm{C}$

UV Spektrumu: $\lambda$ maks. $211(\varepsilon=19400), 223$ (omuz, $\varepsilon=10550)$, $257(\varepsilon=12850) \quad$ ve $295 \quad(\varepsilon=5950) \quad \mathrm{nm}$

NMR Spektrumu: $\delta$ ppm. 0.88 (butil gruplarinın metil protonlar $6 \mathrm{H}, \mathrm{t}$ ), 1.10-2.00 (butil gruplarinın 2 ve 3 . konumlarmdaki metilen protonlar1, 6H,m), 3.00-3.90 (azota bağl1 metilen protonları, 6H,m), 4.08 (metoksil protonları, 6H,s), 4.80 (oksijene bağlı metilen protonları, 2H,t), 6.83 (benzen halkasinın m protonu, 1H,s), 7.00 (benzen 
halkasinın $\mathrm{m}^{\prime}$ protonu, 1H,d), 8.23 (benzen halkasının o' protonu, $1 \mathrm{H}, \mathrm{d})$

Kütle Spektrumu:

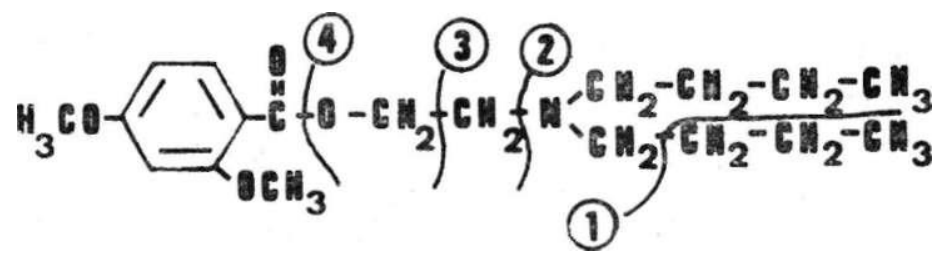

$$
\text { M+ } 337 \text { (Moleküler İyon, \% 6.16) }
$$

1) $\mathrm{m} / \mathrm{e} 294(\mathrm{M}+-43, \%$ 40.62) 2) $\mathrm{m} / \mathrm{e} 209(\mathrm{M}+-128, \% 59.37)$

3) $\mathrm{m} / \mathrm{e} 142$ (Ana pik, \% 100) 4) $\mathrm{m} / \mathrm{e} 165(\mathrm{M}+-172, \%$ 87.50)

\section{Farmakolojik Testler}

Sentezlenen bileşiklerin lokal anestezik etkileri deri duyarlı̆̆ının yitirilmesi esasına dayanan Bülbring ve Wajda yöntemi ile yapılmıştir (6).

Farmakolojik deneyler 500 g civarında olan sağlıklı kobaylar üzerinde yapılmıştır. Kobayların sırtlarında takriben $10 \mathrm{~cm}^{2}$ lik bir alan traş edilmiş, işaretlenen bu bölgeye izotonik sodyum klorür çözeltisinde hazırlanmış 0.1 M çözeltilerden $0.3 \mathrm{ml}$ cilt altına zerk edilmiştir.

Önce etkinin ortaya çıkış süresi bulunmuş ve daha sonra etki süresinin saptanması için bileşiğin verildiği bölgeye iğne batırılarak refleksler gözlenmiştir. Reflekslerin gözlenmesi her 2.5 dakikada bir yapılmış ve reflekslerin geri geldiği anda bileşiğin etkisinin sona erdiği kabul edilmiştir. Deneylerde, duyarlılı̆̆ın geri geldiği süre ile etkinin başladı̆̆ı süre arasındaki fark bileşiğin etki süresi olarak alınmıştır. Kobay üzerinde, bileşiklerin etkisi denenirken her kobaya ay- 
nı zamanda eşit konsantrasyonda prokain hidroklorür de enjekte edilmiş ve her bileşiğin prokain indeksi değerleri şu denklemle bulunmuştur;

$$
\text { Prokain İndeksi }=\frac{\text { Bileşiğin Etki Süresi }}{\text { Prokain HCl'ün Etki Süresi }}
$$

Tablo: 2, sentezlenen bileşiklerin lokal anestezik etki sürelerini ve prokain indeksi değerlerini vermektedir. Tablodan görüldüğü gibi bileşiklerin kantitatif lokal anestezik etkileri yan zincirdeki karbon sayısına bağlı olarak artmaktadır. Zincirdeki karbon sayısı dörtten fazla olduğunda etkinin düştüğ̈ bilindiğinden daha fazla karbon sayılı alkil gruplarını taşıyan yapılar scntczlenmemiştir (7). Yine Tablo'dan anlaşılacağı üzere orto ve para konumlarında metil grubu taşıаan yapılar, metoksil grubu taşıyanlara nazaran daha uzun süreli etki göstermektedir. 2,4- dimetoksibenzoik asitin 2-di-n-butilaminoetil esterinin aynı asitin diğer esterlerine nazaran çok uzun etki göstermesinin sebebi açıklanamamıştır.

\begin{tabular}{|c|c|c|}
\hline $\begin{array}{c}\text { B i l. } \\
\text { No. }\end{array}$ & $\begin{array}{c}\text { Etki } \\
\text { Süresi } \\
\text { (dakika) }\end{array}$ & $\begin{array}{c}\text { Prokain } \\
\text { İnsi }\end{array}$ \\
\hline 1 & 75 & 1.36 \\
\hline 2 & 205 & 3.72 \\
\hline 3 & 200 & 3.63 \\
\hline 4 & 210 & 3.81 \\
\hline 5 & 210 & 3.81 \\
\hline
\end{tabular}

\begin{tabular}{|c|c|c|}
\hline $\begin{array}{c}\text { B i l . } \\
\text { No. }\end{array}$ & $\begin{array}{c}\text { Etki } \\
\text { S üresi } \\
\text { (dakika) }\end{array}$ & $\begin{array}{c}\text { Prokain } \\
\text { Índeks }\end{array}$ \\
\hline 6 & 10 & 0,18 \\
\hline 7 & 40 & 0.72 \\
\hline \hline 8 & 45 & $\mathbf{0 . 8 2}$ \\
\hline \hline 9 & 30 & $\mathbf{0 . 5 4}$ \\
\hline 10 & 195 & 3.54 \\
\hline
\end{tabular}

Tablo 2: Bileşiklerin Lokal Anestezik Etki Sonuçları 


\section{SONUÇ ve TARTIŞMA}

$\mathrm{Bu}$ çalışmada, benzoik asit esteri lokal anestezik etkili bileşiklerde orto konumunda bulunan sübstitüentlerin etkiye olan katkılarının ortaya konulması amaciyla sentezlenen o.p-dimetoksi- ve o,p-dimetilbenzoik asitin 2-dialkilaminoetil esterlerinin sentezleri, yapilarının açıklanması ve kantitatif lokal anestezik etkilerinin tayini ele alınmıştır.

Esterlerin alkol kısmını oluşturan dialkilaminoetil yapılarında alkil grupları metilden n-butile kadar değiştirilmiş; dallanmış bir yapının da etkisinin ortaya konulabilmesi için izopropil grupları da yerleştirilmiştir. Yan zincirdeki karbon sayısı dörtten fazla olduğunda etkinin düştüğ̈ bilindiğinden daha fazla karbon sayılı alkil gruplarının konulmasına gerek duyulmamıştır.

Sentezlenen 10 bileşiğin 7 si ilk kez bu çalışmada yapılmıştır. Bileşiklerin tümünün UV, ÎR, NMR ve Kütle Spektrumları çekilerek yapıları kanıtlanmıştır. Ayrıca, hazırlanan her bileşiğin, deri duyarlılı̆̆ın yitirilmesi esasına dayanan yöntemle kantitatif lokal anestezik etkileri de bulunmuş ve prokain hidroklorür ile mukayese edilmiştir.

Farmakolojik etki sonuçlarına bakıldı̆̆ında, benzen halkası üzerinde orto ve para konumlarında metil grubu taşıyan yapıların metoksil taşıyan analoglarına nazaran daha uzun etkili olduğu anlaşılmaktadır. Bu durumun sebebi ileride yapılacak çalışmalarla açıklanabilecektir. Ancak, orto konumunda bulunan hacimli grupların bileşiğin reseptörden uzaklaşmasını sağlıyarak etkiyi düşürdüğü düşünülmektedir. Orto konumunda bulunan metoksil grubu bileşiğin reseptörden uzaklaşmasını sağlamakta ve bileşiğin reseptöre bağlanması daha güç olduğundan etki düşmektedir.

\section{Lİ T E R A T Ü R}

1- Özden, T., Benzoik Asit Esteri Lokal Anestezik Bileşiklerin Sentez ve Yapı Açıklamaları 1, Ankara Ecz. Fak. Mec, 13, 111-29 (1983)

2- Rohmann, C, Eckert, Th., Synthese und Einige Physikalisch-Chemische Eigenschaften der Diathylaminoathyl Estern von di- und tri alkoxybenzoesauren, Ardl. Pharm., 291, 450-63 (1958) 
3- Sadtler Research Laboratories Inc., Standart Infrared Grating Spectra, Philadelphia, U.S.A., 1972.

4- Barar, F. S. K., Sharma, V. N., The Effect of Three Aminoethyl Esters of Substituted Benzoic Acids on Cardiac, Skeletal and Smooth Muscles, Indian J. Med. Res., 50, 209-17 (1962)

5- Mndzhoyan, A. L., Afrikyan, V. G., Khorenyan, G. A., Lehsenyan, R. A., Marashyan, L. S., Synthesis of p-Alkoxybenzoic Acid Derivatives XXV-III. Aminoesters of W2,4- and 2,6- dialkoxybenzoic Acid, Arm. Khim. Zh, 25 (7), 598-603 (1972)

6- Bülbring, E., Wajda, I., Biological Comparasion of Local Anesthetics, J. Pharmacol. Exptl. Therap., 85, 78-84 (1945)

7- Kalow, W., Hydrolysis of Local Anesthetics by Human Serum Cholinesterase, J. Pharmacol. Exptl. Therap., 104, 22-34 (1952) 